\title{
Somatosensory and Brainstem Auditory Evoked Potentials in the Gunn Rat Model of Acute Bilirubin Neurotoxicity
}

\author{
STEVEN M. SHAPIRO \\ Departments of Neurology, Pediatrics, Physiology and Otolaryngology, Medical College of Virginia \\ Campus, Virginia Commonwealth University Health System, Box 980599 MCV Station, \\ Richmond, Virginia 23298-0599
}

\begin{abstract}
Brainstem auditory evoked potentials (BAEPs) are a sensitive indicator of bilirubin neurotoxicity. Somatosensory evoked potentials (SEPs) have been proposed as another measure of toxicity, though the lemniscal pathways that generate the SEP are not involved in kernicterus. In 16 to 17 -d-old jaundiced (jj) Gunn rats, serial BAEPs and SEPs were obtained up to $8 \mathrm{~h}$ after acute bilirubin toxicity. jjs were injected with $150 \mathrm{mg} / \mathrm{kg}$ sulfadimethoxine to displace bilirubin into brain tissue $(\mathrm{n}=8)$; littermate controls were jjs given saline $(n=4)$ and nonjaundiced given sulfadimethoxine or saline $(n=7)$. After anesthesia, BAEP and SEP recordings were obtained at baseline and serially after injection. SEPs to median nerve stimulation were recorded from surface electrodes over the brachial plexus (Erb's) and contralateral parietal cortex, and subtracted to obtain central conduction time (CCT). There were no statistically significant different baseline values between groups. Baseline BAEP I, I-II, and I-III were $1.22 \pm 0.13,1.11 \pm 0.12$, and $2.10 \pm 0.15 \mathrm{~ms}$, and SEP Erb's and CCT were $1.48 \pm 0.20$ and $5.59 \pm 0.50 \mathrm{~ms}$, respectively $(\mathrm{n}=19)$. At $6.8 \pm 1.5 \mathrm{~h}$ after injection BAEP I, I-II, and I-III increased $0.10 \pm 0.08,0.18 \pm 0.17$, and $0.56 \pm 0.33 \mathrm{~ms}$ over baseline, respectively ( $p=0.005,0.01$, and 0.001 , respectively, paired, 1-tailed $t$-tests), in experimental but not control
\end{abstract}

ABSTRACT

groups. SEP Erb's decreased slightly, $-0.06 \pm 0.04 \mathrm{~ms}$ in experimental and $-0.08 \pm 0.08 \mathrm{~ms}$ in control groups, while CCT did not change significantly. BAEPs were completely abolished in two jjs with no SEP changes. When injection of sulfonamide induced significant peripheral and central BAEP abnormalities in jaundiced rats, no SEP abnormalities occurred. SEPs assess proprioception but not other somatosensory function or sensory integration. The results demonstrate the selectivity of acute bilirubin toxicity for the auditory nervous system. (Pediatr Res 52: 844-849, 2002)

$\quad$ Abbreviations
BAEP, brainstem auditory evoked potential
SEP, somatosensory evoked potential
CCT, central conduction time
jj, homozygous jaundiced Gunn rat
Nj, heterozygous nonjaundiced Gunn rat
sulfa, sulfadimethoxine
MRI, magnetic resonance imaging
PET, positron emission tomography
CNS, central nervous system

Brainstem auditory evoked potentials (BAEPs), also known as auditory brainstem responses (ABRs) are a sensitive indicator of bilirubin neurotoxicity in humans (1-6) and in the jaundiced Gunn rat model of acute bilirubin toxicity (7-11). Somatosensory evoked potentials (SEPs), which assess the somatosensory pathways responsible for joint position and vibratory sensation, have not been thoroughly evaluated in bilirubin neurotoxicity. Abnormal SEPs have been found in human neonates with hyperbilirubinemia (12) in whom prolonged SEP central conduction time was found to correlate with elevated bilirubin levels. Although

February 11, 2002; July 17, 2002.

Correspondence: Steven M. Shapiro, M.D., Box 980599 MCV Station, Richmond, Virginia, U.S.A. 23298-0599; e-mail: sshapiro@hsc.vcu.edu

This work was supported by National Institutes of Health-NIDCD grant R01 DC00369.

DOI: 10.1203/01.PDR.0000036880.02060.EE this finding suggests that the somatosensory nervous system is affected by bilirubin neurotoxicity, there is no pathologic evidence that bilirubin encephalopathy or kernicterus involves structures which generate somatosensory evoked potentials, i.e. the facialis gracilis and cuneatus in the spinal cord, the nucleus gracilis and cuneatus in the medulla, the medial lemniscus in the brainstem, the posteroventral nucleus of the thalamus, the thalamocortical projection, and the cortical structures of the postcentral gyrus of the parietal lobe (13-17).

The jaundiced (jj) Gunn rat is a well-established model of human bilirubin encephalopathy. The jj Gunn rat lacks hepatic uridine glucuronosyl transferase (18), which conjugates bilirubin to form bilirubin glucuronide, and thus has a chronic, lifelong hyperbilirubinemia, which variably produces kernicterus $(19,20)$. 
BAEPs have been studied extensively in jaundiced Gunn rats, and variable degrees of BAEP abnormalities found $(7,8$, 11). To produce acute bilirubin encephalopathy, a sulfonamide is injected into jaundiced Gunn rats. The sulfonamide competes with bilirubin for serum albumin binding sites, and displaces the bilirubin from blood into brain tissue (21). BAEP abnormalities appear within a few hours after injection of sulfonamide into jaundiced Gunn rats (9) and show changes of central conduction that correlate with lesions in the auditory brainstem $(22,23)$.

In contrast, SEPs have not been as extensively studied in either jj Gunn rats or humans. SEPs are generated by electrical stimulation of nerves, and the responses obtained peripherally and centrally are largely generated by the fast-conducting, synchronized proprioceptive somatosensory pathways subserving joint position and vibration (24-27). Bonger-Schokking et al. (12) found a positive correlation of SEP CCT and peak bilirubin level in 3-d-old term human newborns. Silver et al. found prolonged latencies and decreased amplitudes of an SEP cortical component in adult $\mathrm{jj}$ rats but not in young ones (28) and, after sulfadimethoxine injection, found marked latency prolongations in the early components of SEPs in 3-wk-old jjs (29). These SEP changes are surprising, since they are not predicted by neuropathological studies in either the Gunn rat model or humans, and reports of impaired proprioception in patients with kernicterus are lacking.

The well-established model of acute bilirubin neurotoxicity, produced by injecting sulfadimethoxine into 17-d-old jj Gunn rats, has consistently produced the clinical, BAEP and neuropathological abnormalities of kernicterus $(22,23,30-32)$. We decided to first examine SEPs in our model, so that we could then use our model to elucidate the neuroanatomical substrate of any abnormalities. In the present study, serial BAEPs and SEPs were obtained in jaundiced Gunn rats up to $8 \mathrm{~h}$ after acute bilirubin neurotoxicity was induced with sulfadimethoxine injection and verified by the development of typical BAEP abnormalities which have consistently been demonstrated as early as $2 \mathrm{~h}$ after injection $(9,33)$.

\section{MATERIALS AND METHODS}

Experimental Procedure. Homozygous jaundiced (jj) and heterozygous nonjaundiced ( $\mathrm{Nj}$ ) Gunn rats were obtained from jj male $\times \mathrm{Nj}$ female mating pairs in our breeding colony at the Virginia Commonwealth University Health System and studied at $16-17 \mathrm{~d}$ of age. All experimental procedures were reviewed and approved by the Institutional Animal Care and Use Committee of Virginia Commonwealth University and performed in compliance with the National Institutes of Health Guide for the Care and Use of Laboratory Animals. Nonjaundiced $(\mathrm{Nj})$ Gunn rats were anesthetized with an intramuscular injection of ketamine $60 \mathrm{mg} / \mathrm{kg}$ and acepromazine $6 \mathrm{mg} / \mathrm{kg}$, while jaundiced (jj) rats were given 40 and $4 \mathrm{mg} / \mathrm{kg}$, respectively because of their greater sensitivity to the anesthesia. Supplemental anesthesia, one third to one half the initial dose, was given during the recordings for any signs of movement or if muscle activity appeared on an oscilloscope used to continuously monitor scalp electrical activity. Temperature was mea- sured with a rectal temperature probe and held at $37.5 \pm 0.1^{\circ} \mathrm{C}$ with a heating pad and a servo-controlled heating lamp. Baseline recordings were begun $10 \mathrm{~min}$ after the temperature stabilized.

The experimental group consisted of jj rats treated with sulfadimethoxine $150 \mathrm{mg} / \mathrm{kg}$ to displace bilirubin into brain tissue $(n=8)$. Controls were jjs given saline $(n=4)$, and $\mathrm{Nj}$ littermates given either sulfa $(n=3)$ or saline $(n=4)$. After anesthesia, baseline BAEPs and SEPs were obtained, sulfadimethoxine or saline was injected, and serial BAEPs and SEPs recorded for $\geq 6 \mathrm{~h}$ after injection.

Brainstem auditory evoked potential (BAEP) recordings. BAEPs were performed as previously described $(9,33)$. Auditory stimuli were $60 \mathrm{~dB}$ HL monaural $100 \mu \mathrm{s}$ square wave clicks delivered to the right ear at a rate of $14.7 / \mathrm{s}$ through a Sony 4LIS earphone speaker placed at the external auditory meatus. The external canal of the left ear was occluded with earmold impression material (Audalin, Esschem Co., Essington, PA, U.S.A.). Electrode placement for the BAEPs was left mastoid (M1), right mastoid (M2) and vertex (Cz), with a ground electrode placed in the thigh of the left hindlimb. Two simultaneous electrode montages, M1-M2 and Cz-M2, amplified $\times 10^{5}$ and filtered from $0.5 \mathrm{~Hz}$ to $8000 \mathrm{~Hz}$, were obtained, digitized for $10.24 \mathrm{~ms}$ at 512 samples per channel, averaged, and stored on a Nicolet Pathfinder II Evoked Potential System (Nicolet, Inc., Madison, WI, U.S.A.).

For analysis, the latencies of BAEP waves I, II, and III were scored in the M1-M2 montage, and the I-II and I-III interwave intervals were obtained by subtraction of the latency of I from II, and I from III. The I-II and I-III interwave intervals have previously been shown to be extremely sensitive to bilirubin toxicity $(9-11,23,33)$; the Cz-M2 montage was used to confirm BAEP wave identification in the M1-M2 montage.

Somatosensory evoked potential (SEP) recordings. Somatosensory stimuli were superthreshold 5 milliamp, $100 \mu \mathrm{s}$ pulses of electrical current delivered via Grass platinum needle electrodes (Grass/AstroMed, Inc., Quincy, MA, U.S.A.) to the median nerve at the wrist of the right forepaw. Three electrodes were placed circumferentially on the proximal right forelimb and connected to the amplifier ground to reduce stimulus artifact. Location of the primary somatosensory cortex within the parietal lobe of the cerebrum was estimated by extrapolation from stereotaxic maps of adult rat cerebral cortex (34). Preliminary recordings determined that consistent, large, welldefined cortical waves were best obtained from a needle electrode inserted $5 \mathrm{~mm}$ lateral to the midline, at an imaginary line drawn between the apex of the insertion of the two ears anteriorly, and advanced s.c. $5 \mathrm{~mm}$ rostrally, parallel to the midline axis.

Four channel recordings were obtained from four simultaneously recorded electrode pairs placed over 1 ) the ipsilateral clavicle (Erb's point) referenced to the contralateral clavicle, representing activity from the brachial plexus; 2) posterior to anterior neck; 3) ipsilateral parietal somatosensory cortex to contralateral clavicle; and 4) contralateral to ipsilateral parietal cortex. The scalp electrical activity was amplified $\times 10^{5}$, filtered from $0.5 \mathrm{~Hz}$ to $8000 \mathrm{~Hz}$, and digitized for $20 \mathrm{~ms}$ 
following the stimulus at 512 samples per channel, averaged and stored on computer disk.

SEP peripheral latencies were obtained from the initial peak (Erb's) on the ipsilateral-to-contralateral clavicle montage, and the cortical responses from the contralateral-to-ipsilateral parietal lobe electrodes; these latencies were subtracted to obtain central conduction time (CCT), an index of conduction time in the ascending somatosensory system. Erb's wave latency was used to represent peripheral function, and the Erb's-Cortical interwave interval to represent somatosensory CCT.

Statistical analysis. BAEP and SEP values were compared between groups with independent, one-tailed t $\mathbf{t}$-tests. A-priori variables of interest were the I-II and I-III interwave intervals of the BAEP, and CCT of the SEP, with increased conduction time indicating abnormality. Therefore, the changes in conduction time with treatment (i.e. baseline versus the final values) were compared with Fisher's exact, paired, one-tailed $t$-tests. An overall alpha of 0.05 was corrected for three independent, a-priori $t$-tests (BAEP I-II, I-III and CCT) to give an individual alpha of 0.017 as criteria for each of the three comparisons (35). Latencies of the peripheral components, BAEP wave I and SEP Erb's were included for sake of completeness. Since SEP Erb's latency decreased in both experimental and control groups, the significance of this difference from baseline was tested with two-tailed $t$-tests.

\section{RESULTS}

There were no statistically significant differences in baseline BAEP or SEP values between genotypes (jj versus $\mathrm{Nj}$ ) or groups (jj-sulfa, $\mathrm{jj}$-saline, $\mathrm{Nj}$-sulfa or $\mathrm{Nj}$-saline) (Table 1 ). BAEPs and SEPs were recorded serially (Fig. 1), and analyzed at $6.8 \pm 1.5 \mathrm{~h}$ (mean $\pm \mathrm{SD}$ ), median $7.3 \mathrm{~h}$ after injection.

BAEP I latency, and I-II and I-III interwave intervals in the experimental group increased $0.10 \pm 0.08,0.18 \pm 0.17$ and $0.56 \pm 0.33 \mathrm{~ms}$ over baseline, respectively $(p=0.005,0.01$ and 0.001 respectively, paired, one-tailed $t$-tests). Central waves II and III and thus I-II and I-III changed first, followed by changes in the peripheral wave I (Fig. 2A). Amplitude decreased and in some rats all the BAEPs were abolished (Fig. $2 B$ ). There were no significant changes of BAEPs in controls. The BAEP results confirm that injection of sulfa into these $\mathrm{jj}$ rats produced typical, acute bilirubin-induced neurotoxicity.
There was no statistically significant difference in SEP CCT between groups over the course of the experiment, and CCT did not increase significantly over baseline in either the experimental group $(0.015 \pm 0.40 \mathrm{~ms}$ versus baseline, $p=0.92)$ or control groups (Fig. 3). In rats whose BAEPs were abolished, (Fig. 2B) no changes in SEPs were observed.

The SEP Erb's early peripheral response decreased slightly versus baseline in both the experimental group $(-0.06 \pm 0.04$ ms, $p=0.002$, paired, 2-tailed $t$ test) and control ( $-0.08 \pm$ $0.08 \mathrm{~ms}$ in all three control groups combined, $p=0.01$, paired, 2 -tailed $t$ test), but there was no significant difference between groups. The early SEP wave was also identified on the contralateral to ipsilateral parietal electrode pair used to obtain the cortical response (Fig. 1, top, and Fig. 3, left) and baseline values of $1.57 \pm 0.26 \mathrm{~ms}$ in $\mathrm{jjs}$ and $1.54 \pm 0.10 \mathrm{~ms}$ in $\mathrm{Njs}$ were not significantly different from the Erb's latencies recorded from the clavicles, and also decreased slightly in jjs $(-0.08 \pm$ $0.05 \mathrm{~ms}, p=0.003)$ and $\mathrm{Njs}(-0.06 \pm 0.09 \mathrm{~ms}, p=0.06)$. There were no other statistically significant SEP differences in the controls or between control and experimental groups.

\section{DISCUSSION}

Acute bilirubin toxicity produced abnormal BAEPs but no significant change in SEPs in this animal model of acute bilirubin encephalopathy. The results demonstrate the selectivity of bilirubin toxicity for the auditory system since the acute bilirubin neurotoxicity in the jaundiced Gunn rat is selectively associated with peripheral and central auditory but not somatosensory system dysfunction as measured with the SEP technique.

The changes that occur in the BAEP with acute bilirubin neurotoxicity are due to involvement of brainstem auditory structures, e.g. the cochlear nucleus, medial nucleus of the trapezoid body, superior olive, lateral lemniscus, and the inferior colliculus $(15,20,22,30,31,36-40)$. Other structures involved in bilirubin toxicity or kernicterus are the oculomotor nuclei, the CA2 sector of the hippocampus, cerebellum, subthalamic nucleus and the globus pallidus, a part of the basal ganglia (13-15). Abnormalities of the globus pallidus have been found with MRIs in human infants with kernicterus $(41-43)$.

Table 1. BAEP and SSEP latencies and interwave intervals

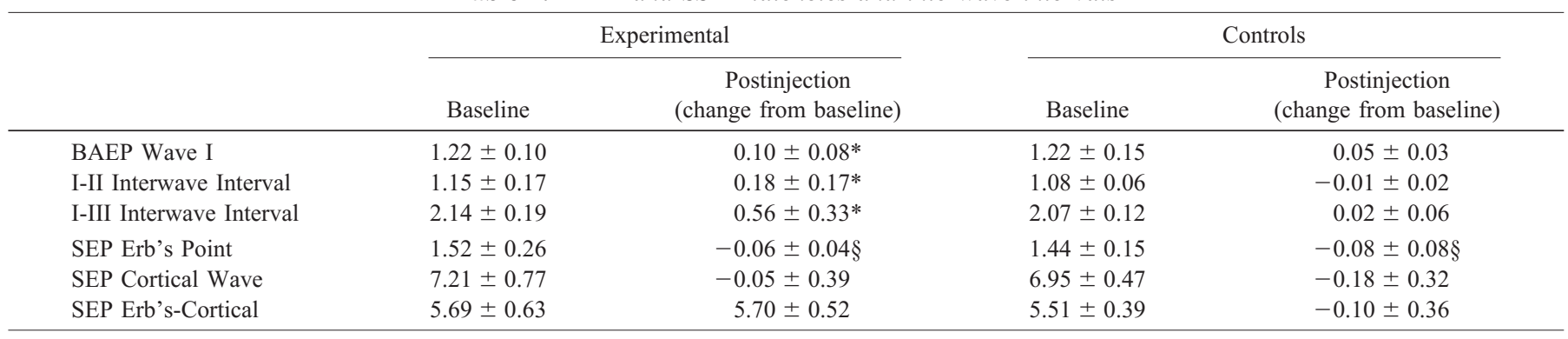

Latencies (msec) in jaundiced (jj) Gunn rats (experimental, $n=8$ ) and in jaundiced and nonjaundiced controls (BAEP, $n=11$; SEP, $n=12)$ before sulfadimethoxine injection (baseline), and change in latencies $6.8 \pm 1.5 \mathrm{~h}$ after injection (postinjection). Note the increased BAEP wave I latency, and the I-II and I-III conduction times in the experimental group.

${ }^{*} p<0.01$ by paired, 1 -tailed $t$-test. $\S p<0.01$ by paired, 2 -tailed $t$-test, see text. 


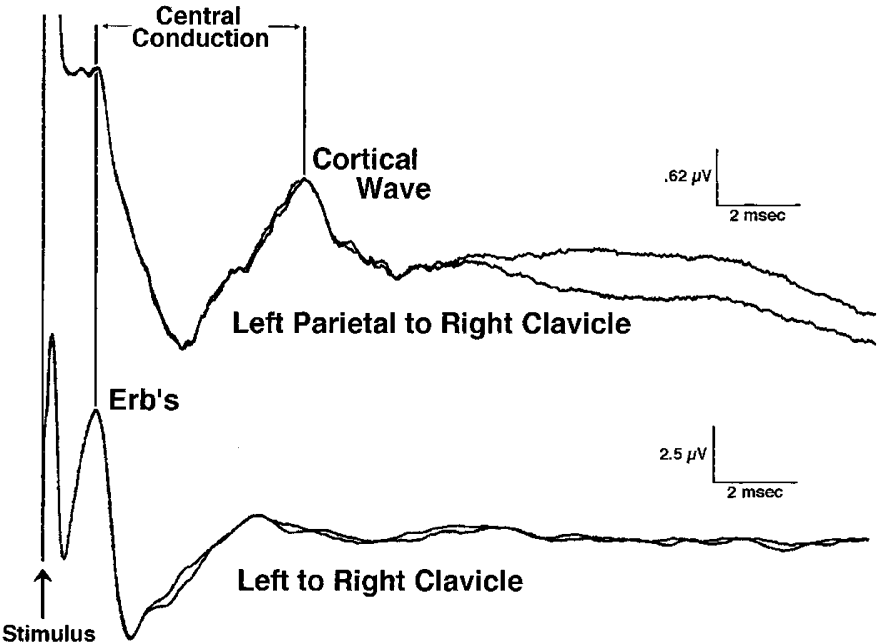

Figure 1. Somatosensory evoked potential (SEP) recordings in a 17-d-old Gunn rat. Two simultaneously differential recordings to right median nerve stimulation are shown, obtained from the left to right clavicle (bottom) and the contralateral parietal cortex to ipsilateral clavicle(top). The Erb's latency is the time from the stimulus to the first peak of the left to right clavicle recording montage (bottom) and the cortical wave latency is the time from the stimulus to the subsequent wave from the contralateral parietal cortex (top). Central conduction is obtained by subtracting the Erb's from the cortical latency.

The proprioceptive or lemniscal system, which generates SEPs in response to median nerve stimulation, enters the CNS from the brachial plexus, ascends in the ipsilateral fasciculus cuneatus in the dorsal columns of the cervical spinal cord to synapse in the nucleus cuneatus in the brainstem, crosses in the medial lemniscus to the ventral posterolateral nucleus of the thalamus, exits via the posterior limb of the internal capsule and courses through the thalamoparietal radiations through the central white matter to the primary somatosensory cortex in the post central sulcus of the parietal lobe $(24-27,44,45)$. Abnormalities of these areas have not been described in kernicterus $(13,15,46)$. Thus, it is not surprising that SEPs remain unaffected while BAEPs are affected.

There are no direct pathways from the globus pallidus to the lemniscal pathways subserving proprioception and other tactile sensations, and PET studies show no basal ganglia activation with unilateral median nerve stimulation (47) or vibrotactile stimulation $(48,49)$. However, a more recent PET study in adult humans has uncovered evidence of a sensory response of the globus pallidus to vibratory stimuli in the absence of motor activity (50). It is hypothesized that the globus pallidus acts as a sensory integrator between the somatosensory and motor systems. Although possible, it is unlikely that this aspect of proprioceptive somatosensory function is assessed by conventional SEPs. Unequivocal pathologic and MRI evidence of damage to the globus pallidus coupled with this new information about the functional role of the globus pallidus in sensory integration suggests that abnormalities of sensorimotor and sensory integration may be present in patients with kernicterus and may be impaired without affecting the SEP.

In our study, both experimental and control groups showed a slight but statistically significant decrease in Erb's latency versus baseline over the course of the experiment. This is most

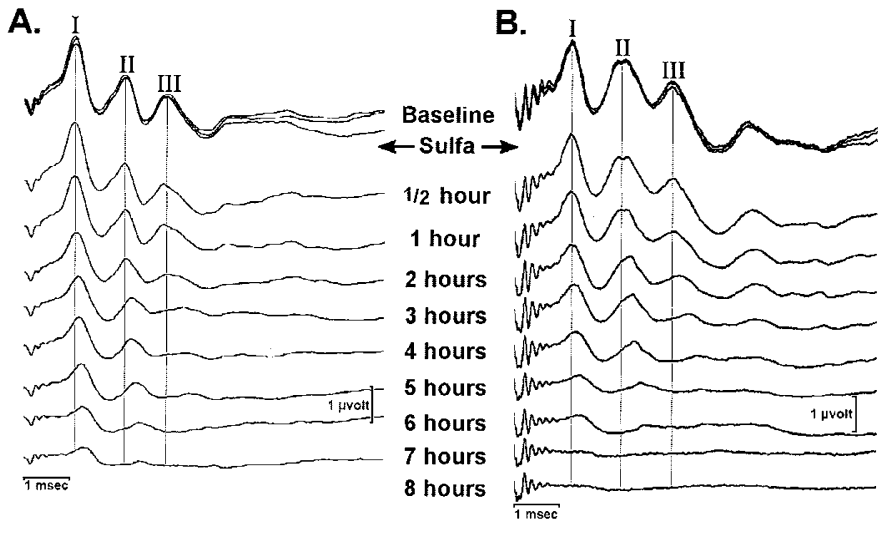

Figure 2. BAEPs in two experimental 17-d-old jaundiced (jj) Gunn rats before (Baseline) and up to $8 \mathrm{~h}$ after sulfa injection to produce acute bilirubin neurotoxicity. $(A)$ In Rat $\mathrm{A}$, note the increased wave latencies and decreased amplitudes with time after injection. $(B)$ In Rat B, BAEPs were abolished with no change in SEPs (see Fig. 3). The abnormal BAEPs confirm that injection of sulfonamide into these $\mathrm{jj}$ Gunn rats produced typical, acute bilirubin-induced neurotoxicity.

likely secondary to an effect of temperature, despite our efforts to control it with a warming pad beneath the rat pup, a servocontrolled heat lamp above, and a 10-min period of temperature equilibration after rectal temperature reached $37.5^{\circ} \mathrm{C}$. We suspect that with anesthesia during the experiment core temperature began to decrease slightly, requiring more radiant heat from the heat lamp to keep rectal temperature stable. This would have the effect of relatively greater warming of the periphery and peripheral nerves. Since nerve conduction velocity is temperature dependent, a warmer temperature would lead to more rapid conduction peripherally and decrease the latency of Erb's response, or the time from the onset of the stimulus in the extremity to the arrival of the afferent volley at the brachial plexus.

The results of this study do not support the finding of Bonger-Schokking et al. (12) who found a positive correlation of CCT and peak bilirubin level in 3-d-old term human newborns with peak bilirubin levels $\geq 250 \mu \mathrm{mol} / \mathrm{L}(\geq 14.7 \mathrm{mg} / \mathrm{dL}$ ). After phototherapy and/or exchange transfusions CCT im-

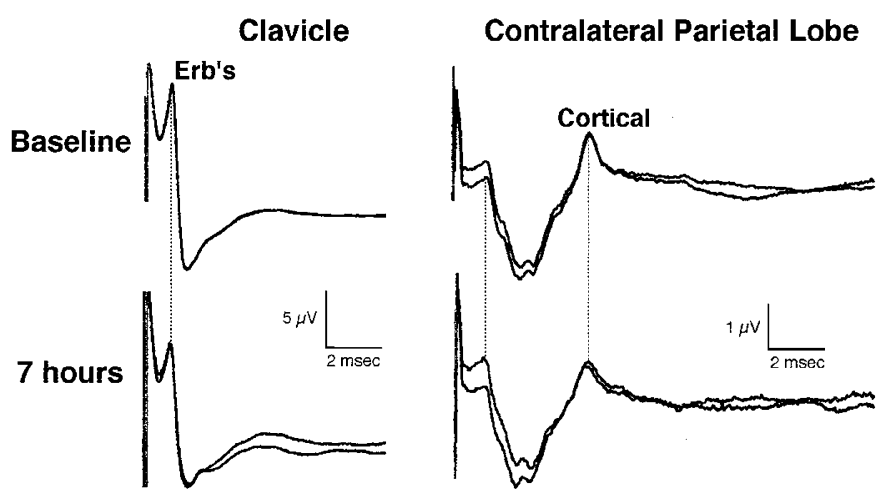

Figure 3. SEPs in an experimental 17-d-old jaundiced (jj) Gunn rat before (Baseline) and $7 \mathrm{~h}$ after sulfa injection to produce acute bilirubin neurotoxicity. No change in SEPs despite dramatic change in BAEPs in the same rat (see Fig. $2 B)$. 
proved but remained elevated; 5 wk later CCT was normal but $\mathrm{N} 13$, a response from interneurons in the cervical spinal cord, was prolonged.

The current study differs from that of Bonger-Schokking et $a l$. in a number of ways. First, pathology in humans and the rat may differ in the way that the somatosensory pathways are involved, with humans more susceptible than rats. However, this finding would be unique, since there is otherwise so much similarity between human pathology and the Gunn rat model, and lemniscal pathway pathology is not described in the Gunn rat $(30-32)$. Second, our experimental animals were studied acutely after bilirubin exposure. Toxicity may develop more slowly in the somatosensory system than in the auditory system, and it is possible that we missed changes that would have appeared later in our rats. Still, it is surprising that $6-8 \mathrm{~h}$ after severe and extreme BAEP changes, not even subtle SEP CCT changes could be demonstrated. Third, the developmental timing of the insult is another possibly important difference. We have shown a developmental susceptibility to bilirubin neurotoxicity in the Gunn rat cerebellum, with areas undergoing differentiation more susceptible than areas that are either more immature or more differentiated (51). Although the 17-d-old rat's auditory system is developmentally comparable to a human neonate's, the rat's motor system is much more mature. Cerebellar atrophy occurs frequently in the jj Gunn rat at about $7 \mathrm{~d}$ of age, and perhaps the rat's sensitive period for SEP pathway damage occurred also at that time, and our acute toxicity studies at $17 \mathrm{~d}$ were performed after the sensitive period for the lemniscal system. However, pathologic studies almost uniformly find evidence of cerebellar atrophy without evidence of damage in the lemniscal pathways, and our findings of no differences in baseline SEPs between $\mathrm{jj}$ Gunn rats and controls suggest that earlier damage to the SEP generators did not occur.

Bongers-Schokking et al. 's measure of CCT differed slightly from ours. They used the difference between the cortical potential and N13, a cervical spinal cord wave, and we used the difference between the cortical wave and the Erb's brachial plexus wave, which is larger, more consistent and easily obtained. Our "central" measure thus includes a small, noncentral peripheral component, namely conduction from the brachial plexus through the ventral roots to the spinal cord. However, Bongers-Schokking et al. also found abnormalities in the absolute latency of their patients' cortical waves, which we did not find in our rats. Further, they reported delays in N13 at $6 \mathrm{~d}$ of age when CCT was abnormal, and again at $5 \mathrm{wk}$ of age when CCT was normal. Our studies used anesthesia, which may affect cortical components and might have blunted the cortical responses so that an abnormality was not observed. However, cortical SEPs are routinely used for intraoperative monitoring with humans and though some increases in latency and decreases in amplitude may be seen, the responses are robust and useful for detecting subtle somatosensory dysfunction.

Technical differences may also have accounted for some of the discrepancies. Bongers-Schokking et al. used extremely restricted filter settings, from $2 \mathrm{~Hz}$ to $100 \mathrm{~Hz}$, whereas our filtering was relatively wide, from $0.5 \mathrm{~Hz}$ to $8000 \mathrm{~Hz}$. The 100
Hz low-pass filter, which they used, would attenuate the amplitudes and alter the latencies of waves with frequencies above $100 \mathrm{~Hz}$, i.e. shorter than $10 \mathrm{~ms}$ in duration. Published methods for SEPs in human infants generally recommend $30-3000 \mathrm{~Hz}$ filter settings (52-59). A low-pass filter setting much below $2500 \mathrm{~Hz}$ results in distortion of SEP components (60), and compared with $3000 \mathrm{~Hz}$, a $1500 \mathrm{~Hz}$ low-pass filter setting has been shown to obscure the earlier cerebral components in infants (59). The restrictive filtering of 2-100 Hz may interfere with accurate detection of peaks or the true wave may disappear entirely, replaced by filter artifact. Finally, BongersSchokking et al. 's reports of significant loss of N13 and N20 SEP amplitude with repeated stimulation have not been verified by others. Since components later than the N20 are subject to fatigability, perhaps their N20 waves were actually later components distorted by restrictive filtering and mistaken for the N20.

Silver et al. (28) recorded SEPs during development and before and after intraperitoneal injection of sulfadimethoxine $100 \mathrm{mg} / \mathrm{kg}$ into $19-23$ day old jj Gunn rats. Early components with positive peaks of $1.19 \pm 0.1 \mathrm{~ms}$ and $3.02 \pm 0.2 \mathrm{~ms}$ were seen, with significant $10 \%$ and $4 \%$ increases of those early components. Cortical waves could not be recorded at all in these animals or in others before $28 \mathrm{~d}$, but were present in adult jjs at $8.5 \pm 0.47 \mathrm{~ms}$ and $\mathrm{Njs}$ at $8.32 \pm 0.49 \mathrm{~ms}$. We did not find abnormalities of early components after sulfa, and had no trouble obtaining the later cortical SEP components in any of our 16-17-d-old rats. There is no obvious explanation of the differences in our findings. They kept temperature less tightly controlled at $36-37^{\circ} \mathrm{C}$ whereas our system controlled rectal temperature more tightly, with a variation of only $0.1^{\circ} \mathrm{C}$ during the experiments. A $1^{\circ} \mathrm{C}$ drop in temperature could account for the increases in latency they saw, and if sick jj rats' temperatures dropped in comparison to their $\mathrm{Nj}$ controls this may have accounted for group differences. Their electrode position to record the early peripheral responses was slightly different from our clavicle-to-clavicle position which is the standard position used clinically to record Erb's response waves (57, 61). However, we re-analyzed our early waves from the nonstandard contralateral to ipsilateral electrode montage, and found the same lack of effect. Finally, in our pilot studies the cortical SEP response was highly sensitive to electrode position, and was reliably obtained only with the positioning technique we described. Silver et al. studied slightly older animals yet were unable to obtain cortical responses, perhaps related to slight differences in positioning technique.

The results of our study demonstrate the selectivity of acute bilirubin toxicity for the auditory system in the Gunn rat model of bilirubin encephalopathy. Our findings of no changes in SEPs in this model are consistent with a lack of histopathological evidence of involvement of the somatosensory pathways which generate the SEP, namely the lemniscal pathways subserving the primary proprioceptive sensations of vibration and joint position in human and animals, and support the selective vulnerability of certain brain regions or systems, e.g. peripheral and central auditory nervous system pathways, for bilirubin toxicity. Additional studies are necessary to determine whether somatosensory evoked potentials are affected by 
more chronic bilirubin toxicity, or whether abnormalities develop with more time after acute exposure, and whether the other somesthetic sensations, sensory integration or sensorimotor integration are affected by bilirubin neurotoxicity and kernicterus.

Acknowledgments. Preliminary experiments and determination of optimal recording technique were performed by Laurie Coggins Han.

\section{REFERENCES}

1. Wennberg RP, Ahlfors CE, Bickers R, McMurtry CA, Shetter JL 1982 Abnorma auditory brainstem response in a newborn infant with hyperbilirubinemia: improvement with exchange transfusion. J Pediatr 100:624-626

2. Perlman M, Fainmesser P, Sohmer H, Tamari H, Wax Y, Pevsmer B 1983 Auditory nerve-brainstem evoked responses in hyperbilirubinemic neonates. Pediatrics 72:658-664

3. Nwaesei CG, Van Aerde J, Boyden M, Perlman M 1984 Changes in auditory brainstem responses in hyperbilirubinemic infants before and after exchange transfusion. Pediatrics 74:800-803

4. Lenhardt ML, McArtor R, Bryant B 1984 Effects of neonatal hyperbilirubinemia on the brainstem electrical response. J Pediatr 104:281-284

5. Nakamura H, Takada S, Shimabuku R, Matsuo M, Matsuo T, Negishi H 1985 Auditory nerve and brainstem responses in newborn infants with hyperbilirubinemia. Pediatrics 75:703-708

6. Gupta AK, Raj H, Anand NK 1990 Auditory brainstem responses (ABR) in neonates with hyperbilirubinemia. Indian J Pediatr 57:705-711

7. Levi G, Sohmer H, Kapitulnik J 1981 Auditory nerve and brain stem responses in homozygous jaundiced Gunn rats. Arch Otolaryngol 232:139-143

8. Uziel A, Marot M, Pujol R 1983 The Gunn rat: an experimental model for central deafness. Acta Otolaryngol 95:651-656

9. Shapiro SM 1988 Acute brainstem auditory evoked potential abnormalities in jaun diced Gunn rats given sulfonamide. Pediatr Res 23:306-310

10. Shapiro SM, Hecox KE 1988 Developmental studies of brainstem auditory evoked potentials in jaundiced Gunn rats. Brain Res 469:147-157

11. Shapiro SM, Hecox KE 1989 Brain stem auditory evoked potentials in jaundiced Gunn rats. Ann Otol Rhinol Laryngol 98:308-317

12. Bongers-Schokking JJ, Colon EJ, Hoogland RA, Van den Brande JL, de Groot CJ 1990 Somatosensory evoked potentials in neonatal jaundice. Acta Paediatr Scan 79:148-155

13. Ahdab-Barmada M, Moossy J 1984 The neuropathology of kernicterus in the premature neonate: diagnostic problems. J Neuropath Exp Neurol 43:45-56

14. Claireaux AE 1961 Pathology of human kernicterus. Montreal: University of Toronto Press

15. Haymaker W, Margles C, Pentschew A 1961 Pathology of kernicterus and posticteric encephalopathy. In: Swinyard CA (ed) Kernicterus and Its Importance in Cerebra Palsy. Springfield, IL: Charles C Thomas, pp 21-229).

16. Zimmerman HH, Yannet H 1933 Kernicterus: Jaundice of the nuclear masses of the brain. Am J Dis Child 45:740-759

17. Yokochi K 1995 Magnetic resonance imaging in children with kernicterus. Acta Paediatr 84:937-939

18. Strebel L, Odell GB 1971 Bilirubin uridine disphosphoglucuronyltransferase in rat liver microsomes: genetic variation and maturation. Pediatr Res 5:548-559

19. Johnson L, Sarmiento F, Blanc WA, Day R 1959 Kernicterus in rats with an inherited deficiency of glucuronyl transferase. Am J Dis Child 97:591-608

20. Johnson L, Garcia ML, Figueroa E, Sarmiento F 1961 Kernicterus in rats lacking glucuronyl transferase. Am J Dis Child 101:322-349

21. Diamond I, Schmid R 1966 Experimental bilirubin encephalopathy. The mode of entry of bilirubin- 14C into the central nervous system. J Clin Invest 45:678-689

22. Conlee JW, Shapiro SM 1991 Morphological changes in the cochlear nucleus and nucleus of the trapezoid body in Gunn rat pups. Hear Res 57:23-30

23. Shapiro SM, Conlee JW 1991 Brainstem auditory evoked potentials correlate with morphological changes in Gunn rat pups. Hear Res 57:16-22

24. Desmedt JE, Brunko E 1980 Functional organization of far-field and cortical components of somatosensory evoked potentials in normal adults. Prog Clin Neurophysiol 7:27-50

25. Desmedt JE, Cheron G 1983 Spinal and far-field components of human somatosensory evoked potentials to posterior tibial nerve stimulation analyzed with oesophagea derivations and non-cephalic reference recording. Electroencephalogr Clin Neurophysiol 56:635-65

26. Fagan ER, Taylor MJ, Logan WJ 1987 Somatosensory evoked potentials: Part I. A review of neural generators and special considerations in pediatrics. Pediatr Neuro 3:189-196

27. Weiderholt WC, Iragui-Madoz VJ 1977 Far field somatosensory potentials in the rat Electroencephr Clin Neurophysiol 42:456-465
28. Silver S, Sohmer H, Kapitulnik J 1996 Postnatal development of somatosensory evoked potential in jaundiced Gunn rats and effects of sulfadimethoxine administration. Pediatr Res 40:209-214

29. Silver S, Sohmer H, Kapitulnik J 1995 Visual evoked potential abnormalities in jaundiced Gunn rats treated with sulfadimethoxine. Pediatr Res 38:258-261

30. Blanc WA, Johnson L 1959 Studies on kernicterus; relationship with sulfonamide intoxication, report on kernicterus in rats with glucuronyl transferase deficiency and review of pathogenesis. J Neuropath Exp Neurol 18:165-189

31. Rose AL, Wisniewski H 1979 Acute bilirubin encephalopathy induced with sulfadimethoxine in Gunn rats. J Neuropathol Exp Neurol 38:152-165

32. Schutta HS, Johnson L 1969 Clinical signs and morphologic abnormalities in Gunn rats treated with sulfadimethoxine. J Pediatr 75:1070-1079

33. Shapiro SM 1993 Reversible brainstem auditory evoked potential abnormalities in jaundiced Gunn rats given sulfonamide. Pediatr Res 34:629-633

34. Hebel R, Stromberg MW 1986 Anatomy and embryology of the laboratory rat: Worthsee, Biomed Verlag

35. Keppel G 1982 Design and Analysis: A Researcher's Handbook, 2 Ed, Englewood Cliffs, NJ, Prentice-Hall

36. Jew JY, Sandquist D 1979 CNS changes in hyperbilirubinemia. Functional implications. Arch Neurol 36:149-154

37. Jew JY, Williams TH 1977 Ultrastructural aspects of bilirubin encephalopathy in cochlear nuclei of the Gunn rat. J Anat 124:599-614

38. Sturrock R, Y JJ 1978 A quantitative histological study of changes in neurons and glia in the Gunn rat. Neuropath Appl Neurobiol 4:209-223

39. Kumada S, Hayashi M, Umitsu R, Arai N, Nagata J, Kurata K, Morimatsu Y 1997 Neuropathology of the dentate nucleus in developmental disorders. Acta Neuropathol (Berl) 94:36-41

40. Ahdab-Barmada M, Moossy J 1983 Kernicterus reexamined. Pediatrics 71:463-464

41. Harris MC, Bernbaum JC, Polin JR, Zimmerman R, Polin RA 2001 Developmental follow-up of breastfed term and near-term infants with marked hyperbilirubinemia Pediatrics 107:1075-1080

42. Martich-Kriss V, Kollias SS, Ball WS, Jr 1995 MR findings in kernicterus. AJNR Am J Neuroradiol 16:819-821

43. Sugama S, Soeda A, Eto Y 2001 Magnetic resonance imaging in three children with kernicterus. Pediatr Neurol 25:328-331

44. Anziska B, Cracco RQ 1980 Short latency somatosensory evoked potentials: Studies in patients with focal neurological disease. Electroencephr Clin Neurophysiol 49:227-239

45. Cracco RQ, Cracco JB, Anziska BJ 1979 Somatosensory evoked potentials in man cerebral, subcortical, spinal, and peripheral nerve potentials. Am J. EEG Techno 19:59-81

46. Malamud N 1961 Pathogenesis of kernicterus in the light of its sequelae. In: Swinyard CA (ed) Kernicterus and Its Importance in Cerebral Palsy. Springfield, IL, Charles C Thomas, pp 230-246.

47. Ibanez V, Deiber MP, Sadato N, Toro C, Grissom J, Woods RP, Mazziotta JC, Hallet M 1995 Effects of stimulus rate on regional cerebral blood flow after median nerve stimulation. Brain 118:1339-1351

48. Coghill RC, Talbot JD, Evans AC, Meyer E, Gjedde A, Bushnell MC, Duncan GH 1994 Distributed processing of pain and vibration by the human brain. J Neurosci 14:4095-4108

49. Burton H, Videen TO, Raichle ME 1993 Tactile-vibration-activated foci in insular and parietal-opercular cortex studied with positron emission tomography: mapping the second somatosensory area in humans. Somatosens Mot Res 10:297-308

50. Boecker H, Ceballos-Baumann A, Bartenstein P, Weindl A, Siebner HR, Fassbender T, Munz F, Schwaiger M, Conrad B 1999 Sensory processing in Parkinson's and Huntington's disease: investigations with 3D H(2)(15)O-PET. Brain 122:1651-1665

51. Conlee JW, Shapiro SM 1997 Development of cerebellar hypoplasia in jaundiced Gunn rats treated with sulfadimethoxine: a quantitative light microscopic analysis. Acta Neuropathol 93:450-460

52. Gibson NA, Brezinova V, Levene MI 1992 Somatosensory evoked potentials in the term newborn. Electroencephalogr Clin Neurophysiol 84:26-31

53. Gilmore R 1992 Somatosensory evoked potential testing in infants and children. J Clin Neurophysiol 9:324-341

54. Aiminoff MJ, Eisen A 1999 Somatosensory Evoked Potentials. In: Aiminoff MJ (ed) Electrodiagnosis in Clinical Neurology, 4th Ed. Churchill Livingston, New York

55. Dumitru D, Robinson LR, Zwarts MJ 2002 Somatosensory Evoked Potentials. In: Dumitru D, Robinson LR, Zwarts MJ (Eds) Electrodiagnostic Medicine, 2nd Ed Hanley \& Belfus, Inc., Philadelphia

56. Dumitru D, Robinson LR, Zwarts MJ (Eds) 2002 Electrodiagnostic Medicine, 2nd Ed. Hanley \& Belfus, Inc., Philadelphia

57. Chiappa KH 1997 Evoked Potentials in Clinical Medicine, 3rd Ed. Lippincott-Raven, Philadelphia

58. Levy SR 1997 Somatosensory Evoked Potentials in Pediatrics. In: Chiappa KH (ed) Evoked Potentials in Clinical Medicine, 3rd ed. Lippincott-Raven, Philadelphia, pp 453-469

59. George SR, Taylor MJ 1991 Somatosensory evoked potentials in neonates and infants: developmental and normative data. Electroencephalogr Clin Neurophysio 80:94-102

60. Desmedt JE, Brunko E, Debecker J, Carmeliet J 1974 The system bandpass required to avoid distortion of early components when averaging somatosensory evoked potentials. Electroencephalogr Clin Neurophysiol 37:407-410

61. Guideline nine: guidelines on evoked potentials. American Electroencephalographic Society. 1994 J Clin Neurophysiol 11:40-73 